\title{
SISTEMA CONCEPTUAL E SISTEMA TERMINOLÓGICO
}

\author{
Maria Aparecida Barbosa
}

RESUMO: Este trabalho propõe-se a examinar aspectos importantes dos niveis conceptual, lexemático e terminológico do percurso gerativo da enunciação de codificação e de decodificação. $O$ estudo das estruturas e funçōes das unidades-padrão do plano cognitivo e do plano semiótico tem grande relevância, no âmbito das pesquisas lexicológicas, semânticas e terminológicas. São analisadas, aqui, de um lado, a complexidade estrutural e funcional dos constructos do primeiro nivel - arquiconceito, metaconceito, metametaconceito -, com vistas à proposição de uma tipologia de campos conceituais; de outro, são examinadas diferenças conceituais e metodológicas entre conceito e definição. enquanto subsídios para a metodologia de configuração de traços semântico-conceptuais de um conceito.

UNITERMOS: arquiconceito; conceito; metaconceito; Semântica Cognitiva; Semântica Lexical.

RESUME: Ce travail se propose d'examiner quelques aspects des niveaux conceptuel, lexematique et terminologique du parcours génératif de l'énonciation de l'encodage et du decodage. L'étude des structures et des fonctions des unitésstandard du plan cognitif et du plan sémiotique est très important, dans le cadre des recherches lexicologiques, sémantiques et terminologiques. On analyse ici, d'un côté, la complexité structurale et fonctionnelle des formations du premier niveau - archi-concept, méta-concept, méta-métaconcept, ayant en vue la proposition d'une typologie des

- Faculdade de Filosofia, Letras e Ciências Humanas, Universidade de São Paulo, Brasil.

TRADTERM, 7, 2001, p. 71-94 
champs conceptuels; d'un autre côté, on examine encore des différences conceptuelles et méthodologiques caractérisant le concept et la définition, de manière à obtenir des éléments pour la proposition d'une méthodologie permettant de formaliser les traits sémantico-conceptuels d'un concept donné.

MOTS-CLÉS: archi-concept; concept; meta-concept; Sémantique Cognitive; Sémantique Lexicale.

\section{Introdução}

A articulação entre a semântica cognitiva e a semântica lingüistica tornou-se um dos paradigmas das ciências da linguagem, em sua fase pós-moderna. Acreditamos, pois, da maior importância o desenvolvimento de modelos que possibilitem analisar e descrever o patamar da cognição e suas relações com o patamar da semiotização lingüistica, especificamente, neste artigo, com o da terminologização (Barbosa, 1998a, p.25-44).

Assim, nós nos propusemos, neste trabalho, a examinar aspectos importantes dos niveis conceptual, lexemático e terminológico do percurso gerativo da enunciação de codificação e de decodificação. Analisamos, aqui, de um lado, a complexidade estrutural e funcional dos constructos do primeiro nivel - arquiconceito, metaconceito, metametaconceito; de outro, examinamos diferenças conceituais e metodológicas entre os processos de conceituar e de definir, de modo a obter subsidios, para uma metodologia de configuraçāo dos traços semântico-conceptuais de um conceito. Isso torna possivel, ainda, a caracterização de diferentes tipos de contextos, discursos manifestados em que são engendrados conceitos, por distintos processos. Tais contextos constituem as principais fontes de que são extraidos os correspondentes traços semântico-conceptuais. Com efeito, é na instância discursiva que se produz a cognição e a semiose. se instaura a conceptualização de um 'fato', se engendra um conceito e sua manifestação lingũistica. É no discurso manifestado, pois, que se presentificam os traços conceptuais, num procedimento de codificação; e é dele que se extraem, num procedimento de investigação, esses mesmos traços. 


\section{Conceptualização e percurso gerativo da enunciação}

Os termos conceituar e definir, conceito e definição, não raras vezes, são indevidamente empregados uns pelos outros e, até mesmo, considerados equivalentes. Essa relação de equivalência, entretanto, não se justifica, eis que são grandezas que têm qualidades conceituais especificas, constituindo, inclusive, unidades-padrão e processos de distintos niveis do percurso gerativo da enunciação de codificação e decodificação (Pais, 1993, p.562578).

De fato, esse percurso inicia-se com a percepção dos "fatos naturais", que, sendo substâncias estruturáveis enquanto informação potencial para os homens, convertem-se, contudo, em substâncias estruturadas quando, mesmo mantendo um núcleo de percepção biológica universal, são apreendidas pelos grupos lingüisticos e socioculturais de diferentes maneiras. Esse primeiro momento, da percepção, desencadeia um segundo momento: o de início do processo de conceptualização, ou da passagem da percepção à conceptualização. Esta compreende, por sua vez, nesse estágio, três tipos de atributos semânticos: o das latências, em que os fatos observáveis têm os seus traços identificadores em estado potencial, enquanto substâncias de conteúdo (Hjelmslev, 1975, p.53-64) estruturávels, apreensiveis; o das saliências, em que certas características dos fatos se destacam por si mesmas, na semiótica natural; e o das pregnâncias, em que o sujeito enunciador individual e/ou coletivo seleciona e escolhe os traços que irão configurar o conceito que têm do fato em questão (Pottier, 1992, p.61-69). O terceiro momento, em que se conclui o processo de conceptualização (Pais, 1993, p.569-578), è o da produção dos modelos mentais, dos conceptus (Rastier, 1991, p.73-114), noções ou conjuntos noêmicos - traços semânticos conceptuais -, a que correspondem, por seu turno, os recortes culturais, os recortes construídos, em última análise, os designata.

Esses três momentos - da percepção, do início e do fim da conceptualização - constituem, assim, o próprio percurso da cognição, entendido como a apreensão e construção de uma "vlsão de mundo". 
Para Cabré (1993, p.94-96), “... la relación referente-conceptouno de los ejes cuyo estudio presenta mayor dificultad cientifica, ya que solo es abordable a partir de hipótesis y comprobaciones empíricas indirectas; supone describir de qué modo los individuos conocen la realidad, cómo la perciben y cómo la conceptualizan. Esta relación es todavia hoy un tema muy controvertido. La polémica sobre si la realidad existe por si misma de forma objetiva, o si por el contrario existe solo a través de la percepción, no está todavia lo suficiente resuelta. Lo cierto es que los individuos aprehenden la realidad mediante los distintos subsistemas de cognición, $y$ en consecuencia se comportan de acuerdo con esta aprehensión (por ejemplo, evitan lo que consideran peligro, eligen los alimentos que les gustan, se orientan en un determinado espacio, etc.). Paralelamente, utilizan los sistemas expresivos, entre los que el lenguaje ocupa el lugar más importante, para aludir a esa realidad (...). La cognición es el resultado de un proceso psiquico que conduce al conocimiento. El problema de cómo el pensamiento humano comprende los objetos, y por abstracción, construye los conceptos, se encuentra en la misma base de la teoria terminológica. La cognición es un proceso mental que consiste en aprehender la realidad. Una teoria cognitiva de la terminología deberia ser capaz de explicar tres cuestiones básicas sobre el conocimiento relacionadas entre sí: a) cómo los individuos conceptualizan la realidad y estructuran el conocimiento; b) qué son los conceptos, cómo se establecen, cómo se interrelacionan y cómo se ordenan en la estructura del conocimiento; c) cómo se relacionan los conceptos y los términos".

\section{Lexemização, atualização, semiose}

O quarto momento do percurso gerativo da enunciação de codificação é, pois, o da lexemização e da terminologização, ou seja, corresponde à conversão do conceito em grandeza-signo, em que se deixa o nivel cognitivo, para se passar ao nivel semiótico propriamente dito. A lexemização é aqui entendida como "la mise en lexème", e terminologização como "la mise en terme", ou seja, a configuração do conceito em grandeza-signo, no próprio ato de instaurar a significação. Dessa forma, o metassistema conceptual, 
o mesmo para todas as semióticas-objeto de uma cultura, produz conjuntos de semas conceptuais que desempenham o papel de matrizes signicas para os diferentes sistemas semióticos de uma mesma cultura, de uma macrossemiótica, em suma, por meio dos processos de semiologizaçāo, lexemizaçāo, terminologização e semiotização. Nessas condições, de acordo com Pais (1993, p.188), os conceptus ou lexes devem ser considerados como lexias em potencial, configurando-se como ponto de partida do processo de lexemização e de terminologização. Nessa perspectiva, o metassistema lexemático, ou terminológico, conjunto das lexias com suas expressões e conteúdos (sobressememas ou sememas polissêmicos), sua rede de relações, constitui, por sua vez, uma instância de competência que precede e autoriza a atualização da lexia num discurso concretamente realizado.

Nesse quinto momento, da contextualização, tem-se um epissemema (simultaneamente, com a redução dos semas do sobressemema, ou seja, a seleção, determinada por uma situação de discurso e de enunciação, e o acréscimo de semas do contexto, na combinatória sintagmática), de que resulta a semiose.

Como se verifica, a grandeza conceito situa-se num nivel prélingüistico, ou, mais exatamente, pré-semiótico de designação, podendo mesmo existir sem a respectiva denominaçāo, já que se pode ter a percepção e o conhecimento de um fato, sem se possuir, ainda, a sua respectiva denominação. De fato, os conceitos mantêm diferentes tipos de relações com as denominaçōes: há, como dissemos, conceitos sem denominações; há conceitos com apenas uma denominação; há conceitos com duas ou mais denominações, sendo ainda possivel que uma mesma denominação comporte dois ou mais conceitos. Cumpre observar, com Cabré (1993, p.172), que a vertente formal da unidade terminológica recebe em terminologia o nome de denominação (e também o de termo) e que, ainda que o termo se preste propriamente para designar a unidade terminológica completa (o conjunto formado pela denominação e pelo conceito), também se utiliza como sinônimo de denominação.

Esse ciclo prossegue, então, com o fazer interpretativo do sujeito enunciatário, a que se seguem a recuperação e a armazena- 
gem da informação, que desencadelam, por sua vez, um subseqüente processo de conceptualização.

\section{Conceituar e definir}

Considerando esse percurso, Pottier (1981, p.59) mostra a necessidade de, pelo menos, quatro niveis de análise: a) nivel referencial, do mundo real ou imaginário (objetos, sonhos, memória do discurso de outrem, foto...); b) nivel conceptual, de apreensão mental, da representação construida a partir do referencial, ao mesmo tempo tributárla dos hábitos socials e das necessidades crlativas individuais; c) nivel da lingua natural, da competêncla lingüistica em seu conjunto; d) nivel do texto produzido, resultado de diversos componentes (lingüístico, cognitivo, contextual, situacional, intencional), em correlação possivel com outros sistemas semióticos (gestos, proxêmica, llustraçōes...).

Nessa perspectlva, a ontologia é a disciplina que trata do primeiro nivel, ou seja, dos "objetos", de suas caracteristicas, organizaçāo e rede no universo natural; a conceptologia, no âmbito da lógica, ocupa-se da natureza dos conceitos, de sua representação e das relações que se estabelecem entre eles; a noêmica se define, então, como o estudo dos elementos conceptuais e de suas relaçōes, considerados como instrumentos necessários, para descrever o funcionamento da semântica de base das linguas naturais. Interessam-nos, aqui, desse ponto de vista, a conceptologia e a noèmica.

Uma vez definidos esses niveis de codificação e de análise, parece possivel delimitar com malor rigor as grandezas conceito/ definição, os processos de conceituar/definir.

Se o conceito, como vimos, estabelece-se num nivel pré-lingüistico, a definição resulta de uma análise e descrição de grandezas signicas, situando-se, pois, no nivel semiótico, pelo menos no que diz respeito ao seu ponto de partida. Com efeito, o conceito é o resultado de uma interpretação de fatos naturais e/ou culturais, enquanto a definiçāo é o resultado de uma interpretação de unidades lexicals. Conceltuar é o processo de construção de um modelo mental que corresponde a um recorte cultural e, em 
seguida, de escolha/engendramento da estrutura léxica que pode manifestá-lo de maneira mais eficaz. Tal processo tem como ponto de partida o universo natural. Definir é o processo de analisar e descrever o semema lingüistico, para reconstruir o modelo mental: o seu ponto de partida é a estrutura lingüistica manifestada.

É interessante ressaltar que o percurso gerativo é realizado não somente pelo sujeito enunciador que cria um vocábulo e/ou termo novo, mas também por esse sujeito, ao reutilizar vocábulos e/ou termos pré-existentes, em qualquer situação de atividade lingüística. A cada ato de fala, há uma reorganização do sistema lingüístico e do metassistema conceptual. Segundo Cabré (1993, p.100), a maioria dos conceitos não tem fronteiras rigidamente estabelecidas mas limites aproximados e difusos. Com a normalização, os conceitos passam a definir artificialmente seus limites. Configura-se, assim, o caráter instável e dinâmico do nivel cognitivo, de forma que a estrutura do conhecimento pode mudar fundamentalmente por duas causas: seja porque aparece um novo eixo, levando todos os conceitos anteriores a redefinirse em função dessa nova dimensão; seja porque surge uma nova forma de ver as coisas, de sorte que os conceitos pré-existentes não mudam de eixo mas mudam de posição no seu eixo.

Observe-se que os atos de conceituar, ou de engendrar um discurso manifestado qualquer - são processos onomasiológicos tomam como ponto de partida o continuum amorfo dos dados da experiência, passam pelo nivel noêmico e chegam ao nivel lexemático, que vai do fato ao nome, e cujo produto é a denominação. É o percurso do fazer persuasivo do sujeito de enunciação de codificaçāo, desencadeado por quem fala, quem escreve. Esse sujeito de enunciação de codificação, tendo uma intenção de comunicação de determinado esquema lógico-conceptual, pode selecionar diferentes formas lingüisticas, suscetiveis de representálo, para engendrar o seu discurso enfim manifestado. Essa escolha integra o processo de modalização do discurso, enquanto competência e desempenho do sujeito enunciador. Desse percurso resultam: conceitos, seus representantes semiotizados - grandezas-signos - presentificados, em etapas posteriores, em discursos manifestados. 
Cumpre ressaltar, ainda, que o processo de construção de um conceito pode ser "vertical" - do "fato" para o patamar cognitivo ou pode ser desencadeado nas relaçōes sintagmáticas de um discurso manifestado, em que o autor vai pouco a pouco construindo, no seu texto, um conceito qualquer. No segundo processo, a combinatória das palavras-ocorrência vai paulatinamente configurando o recorte conceptual que o autor tem de um "fato".

De outro ângulo, tem-se o percurso que toma como ponto de partida o discurso manifestado, para chegar novamente ao nivel conceptual, que caracteriza o fazer interpretativo do sujeito enunciatário, ou, noutras palavras, um processo semasiológico, do signo para o conceito, realizado por quem ouve ou quem lê; qualifica-se, assim também, o percurso lexicográficoterminográfico, enquanto processo que parte da manifestação do nivel lexemático, com as seleçōes, restrições e combinatórias sêmicas estabelecidas em discurso, para, num metadiscurso igualmente configurado como fazer interpretativo, articular semas representados por metatermos lexemáticos, operaçāo de que resulta a definiçāo.

\section{A organização dos patamares conceptual e lexical}

É importante ressaltar que existem diferentes tipos de campos conceptuais e de campos lexicais, bem como relações que se estabelecem entre os elementos do conjunto dos primeiros e os do conjunto dos últimos, e que há diferenças nocionais e estruturais entre campo conceptual, campo lexical, campo semântico e respectivas unidades-padrão: conceito, lexemas/vocábulos/termos, sememas.

Essa questão insere-se, como vimos nos itens anteriores, no modelo do percurso gerativo de enunciação de codificação e de decodificação, pois cada um daqueles campos situa-se em diferentes patamares desse percurso: o campo conceptual, conjunto de conceitos, é resultado do processo de conceptualizaçāo do 'saber sobre o mundo' - pré-lingüistico, pré-semiótico, transsemiótico; o campo lexical, conjunto de lexemas, lexias, vocábulos/termos que têm um núcleo sêmico comum, resulta do pro- 
cesso de lexemização - conversão da informação conceptualizada em significação lingüística; o campo semântico, em uma de suas acepções, constitui um conjunto de sememas e resulta da intersecção do significado das unidades lexicais de um campo lexical. As relações existentes entre os três campos não são simétricas, visto que um campo lexical pressupōe e contém necessariamente os seus correspondentes campo conceptual e campo semântico, ao passo que um campo conceptual pode não ter, ainda, os campos lexicais e semânticos que lhe corresponderiam. Constituem, pois, constructos não confundiveis, na medida em que pertencem a niveis de articulação e de análise distintos (Barbosa, 1999, p.29-52). Desses três tipos de campos, apresentaremos, aqui, apenas a organização do campo conceptual.

\section{Estruturação do patamar conceptual}

Um conceito, em sentido amplo, constitui, conforme expusemos acima, um "modelo mental", conceptus (Rastier, 1991, p.73114), dialeticamente articulado a um recorte cultural ou designatum. É um conjunto de traços semânticos conceptuais que, em nossa concepção, apresenta grande complexidade estrutural: um subconjunto de noemas (Pottier, 1992, p.61-69), biofisicos ou "universais", conceito stricto sensu; um subconjunto de traços semânticos conceptuais ideológicos, culturais, metaconceito; um subconjunto de traços semânticos conceptuais ideológicos, intencionais, modalizadores, metametaconceito. Neste último, o noema [intenção] é o mais importante, por oposição ao [ideológico] do subconjunto anterior, não tão marcado como o [intencionall. Esses três subconjuntos formam o conceito lato sensu (Barbosa, 2000, p.95-120).

Campo conceptual como conjunto unitário

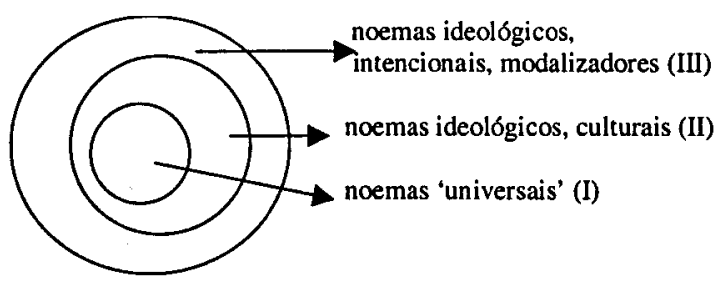

Figura 1

TRADTERM, 7, 2001, p. 7:1-94 
Julgamos importante ressaltar que, ao se engendrar um conceito, geram-se, simultânea e necessarlamente, três outros conceitos: seu contrário e os contraditórios decorrentes, já que o raciocinio do homem funciona por oposições, dentre as quais, relaçōes entre contrários e contraditórios.

Desse modo, ao crlar-se o conceito <<bem $\gg$, por exemplo, concomitantemente engendra-se o seu contrário, $<<$ mal $>>$, e seus respectivos contraditórios, $<<\sim$ bem $\gg$ e $<<\sim$ mal $\gg$ :

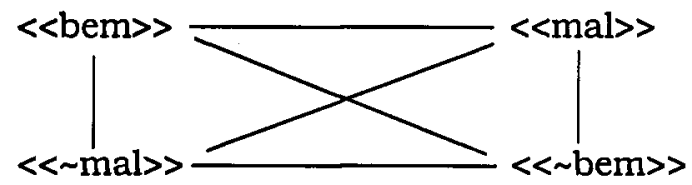

\section{Figura 2}

Essas relações "necessárias" e "não-eventuais" nos autorizam a conceber o processo da intertextualidade lato sensu como iniciando-se já no patamar conceptual do percurso gerativo da enunciação, pols um concelto liga-se necessariamente a outro conceito, constituindo um microssistema conceptual.

Assim, um concelto lato sensu é um campo conceptual, já que, implicitamente contém esses três outros conceitos. Chamaremos esse caso de campo conceptual unitário pleno, por oposição ao campo conceptual unitário vazio $(\varnothing)$ ). o que contém conceitos virtuais ainda não engendrados.

Diferente é a organização do campo conceptual conjunto múltiplo, que contém vários conceitos lato sensu explicitados, com um núcleo sèmico comum, apresentando, cada um deles, implicitamente, seus conceitos contrários e contraditórios.

Retomando o subconjunto de noemas "universais", que aqui denominamos conceito stricto sensu, numa outra perspectiva - a da análise contrastiva, entre grupos socioculturais diferentes, e a da análise comparativa, entre subgrupos de uma mesma cultura -. chegamos à noção de arquiconceito, resultante da neutrallzaçāo da oposição existente entre concepçōes diferentes de um mesmo "fato". 
O conjunto de traços semânticos conceptuais de natureza "universal" corresponde a um arquiconceito (Béjoint e Thoiron, 1996, p.512-526), já que neutraliza as diferenças conceptuais entre linguas diferentes. Estaria relacionado o arquiconceito ao protótipo (Dubois, 1991) e à intersecção do sentido recortado culturalmente ou formado (Hjelmslev, 1975, p.53-64). Sustenta e viabiliza os processos de tradutibilidade interlingüistica $e$ intersemiótica.

Se compararmos o recorte conceptual de um "fato" natural, de uma língua $A$ e de uma lingua $B$, diremos que os traços comuns constituem o seu arquiconceito, que denominaremos arquiconceito. . Logo:

$$
\begin{aligned}
& \text { arquiconceito }_{1} \subset \text { conceito }_{1} \text { de lingua } \mathrm{A} ; \\
& \text { arquiconceito }_{1} \subset \text { conceito }_{1} \text { de lingua } \mathrm{B} .
\end{aligned}
$$

Segundo Bejoint e Thoiron, "l'archi-concept est vu ici comme une entité abstraite dont le statut, au plan philosophique, ne nous concerne pas. On reconnaitra seulement que l'archi-concept est en correspondance dans les diverses cultures, avec divers concepts. Le degré de similitude entre concepts, dits ici homologues, n'est pas préjugé (i.e. ni sous-estimé ni décrété a priori): il peut être grand ou faible (...) ceci permet de reconstruire, pour chacune de ces langues, un embrion de concept. La réunion de ces ensembles embrionnaires de traits conceptuels constituerait l'embrion d'un archi-concept... " (1996, p.516-617). A última parte da citação nos remete inclusive ao processo de passagem do sentido amorfo, estruturável, ao sentido formado, estruturado (Hjelmslev, 1975, p.53-64), porém comum, mutatis mutandis.

Diriamos, pois, que o processo de conceptualização, como percurso, é muito mais complexo do que a passagem do "sentido amorfo" para o "sentido formado", tal como o explica Hjelmslev. Há etapas teóricas constitutivas do processo de conceptualização, entre um e outro. Com efeito, na passagem do patamar da percepção ao da conceptualização, há, como vimos, três estágios de atributos semânticos: as latências, atributos semânticos possiveis dos 'objetos' e 'processos' da semiótica natural; as saliências, 
atributos que se destacam, na estrutura, funcionamento e hierarquia dos "fatos naturais" ("o perceber"); as pregnâncias ("o conceber"), por sua vez, constituem o resultado da atividade do homem, das escolhas que faz na apreensão daqueles "fatos" (Pais, 1999, p.13-50).
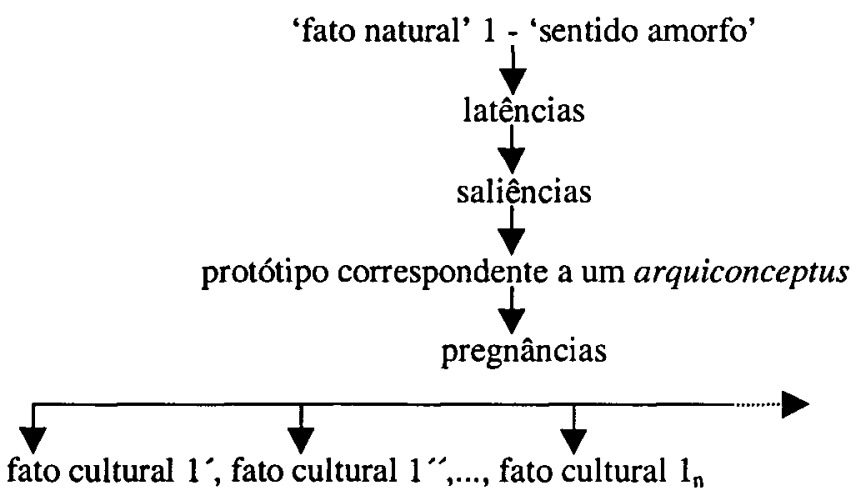

'sentido formado'

\section{Figura 3}

Assim, entre o sentido estruturável e o sentido estruturado, há a formação de um protótipo conceptual biofísico, núcleo noèmico comum a todas as culturas, que corresponderia ao arquiconceito, ou conceito stricto sensu, primeiro nivel de "formação", resultante das latências e salências. Entretanto, no processo de pregnâncias, começam a ficar visiveis os noemas culturais, específicos de cada cultura, correspondentes ao metaconceito, segundo nivel de "formação". Por fim, no interior de uma mesma cultura, os discursos "políticos" eufóricos ou disfóricos sobre o mesmo fato engendram o metametaconceito, subconjunto dos traços semântico-conceptuais modalizadores.

Parece-nos que a noção de arquiconceitoé fundamental, quando da análise contrastiva de línguas e culturas e também no âmbito da mesma língua e cultura, no exame da variação conceptual do mesmo "fato": assegura o rigor do estudo da variabilidade e das identidades conceptuais do mesmo "fato" entre culturas e entre grupos. Cremos que essa noção de arquiconceito 
completa as formalizações já existentes, que descrevem as estruturas do patamar cognitivo. É de se ressaltar, ainda, o isomorfismo, ou identidade formal entre os processos de neutralização fonológica, morfológica, lexical, semântica, conceptual, mesmo textual e seus respectivos produtos: arquifonema, arquimorfema, arquilexema, arquissemema, arquiconceito e arquitexto, este últtmo (Rastier, 2000, p.445-470), resultado da neutralização das diferenças existentes entre textos implicados num processo de intertextualidade.

As reflexões acima nos autorizam a propor uma tipologia de campos conceptuais (Barbosa, 2000, p.95-120), segundo o critério do número de elementos, da qualidade e quantidade de elementos que contêm: campo conceptual como conjunto unitário, campo conceptual como conjunto vazio, campo conceptual como conjunto múltiplo, este último, por sua vez, constitutivo de quatro tipos, o dos co-hipônimos da "semiótica natural", o dos co-hipônimos culturais, o dos co-hipônimos modalizadores e o dos parassinônimos.

\section{Um modelo de engendramento e estruturação de um concei- to lato sensu: a formação conceptual de <<transgênico〉>}

À guisa de ilustração, apresentamos a formação do conceito de transgênico, na cultura brasileira. Transgênico é um termo técnico de grande atualidade e, como adjetivo, serve para qualificar seres biológicos, modificados em sua estrutura genética, através de tecnologias desenvolvidas pela engenharia genética. No seu núcleo sêmico conceptual, temos os semas conceptuais [+ser vivo], [+biologia], [+genética], [+estrutura], [+engenharia], [+tecnologia], [+mutação]. Aplica-se preferencialmente à produção de alimentos. Os atributos semêmicos e semânticoconceptuais, nesse nivel, configurariam a intersecção de todos os seres vivos e produtos transgênicos, no nivel biológico e técnico, ou seja, o seu arquiconceito.

Contudo, essa inovação nas técnicas de produção e, conseqüentemente, nos hábitos de consumo, desencadeou em nivel mundial e, particularmente em nosso país, ampla discussão. De um lado, temos os áulicos da "modernidade" que defendem a produção e consumo de alimentos transgênicos, acentuarido os 
semas conceptuais [+modernidade], [+produtividade], [+fartura], [-preço]. De outro lado, temos biólogos, médicos e ecologistas, dentre outros, que apontam possiveis perigos da inovação e que realçam, por seu lado, os semas [+ser vivo], [+biologia], [+alimento], [+natural], [+saudável]. [+seguro], [+preservação], [+meio amblente], [+tradição] dos produtos alimenticios naturais, correspondentes, no nivel cognitivo, ao metaconceito.

A questão envolve problemas políticos, econômicos e sociais relevantes. Sucedem-se discursos favoráveis ou contrários, em tom sereno ou veemente, que compreendem semas conceptuais intencionais, modalizadores, manipulatórios, como, por exemplo, a oposição [+modernidade] / [+preservação], [+lucro] / [+saúde pública], dentre outros, correspondentes, por sua vez, no nivel cognitivo ou hiperprofundo, aos conjuntos semântico-conceptuais dos metametaconceitos.

$\mathrm{Na}$ análise dos discursos sobre essa temática, é possivel detectar as tensões e conflitos em jogo no patamar da semântica profunda - do percurso gerativo da enunciação de codificação e decodificação (Pais, 1998, p.271-311) - de modo a formalizar os microssistemas de valores subjacentes a esses discursos. Num modelo semiótico dialético, temos, em semântica profunda:

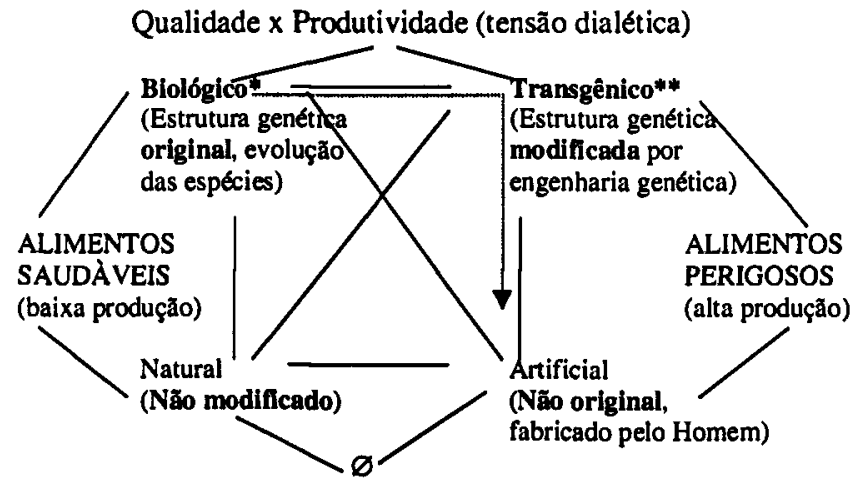

Termo neutro, nem natural, nem artificial (fora do sistema)

* Biofato ** BIOMANufato

\section{Figura 4}


Biológico implica natural, transgênico implica artificial. Biológico $x$ transgênico coexistem e sustentam-se numa tensão dialética, na época atual. Um percurso dilético possivel desse modelo semiótico seria: a partir do biológico, a engenharia genética cria um transgênico, que implica um artificial, nāo-natural. A combinação biológico $x$ natural constitui a dêixis positiva alimentos saudáveis; a combinação transgênico $x$ artificial constitui a dêixis negativa alimentos perigosos. Os percursos dialéticos através dos eixos dos contrários, contraditórios e subcontrários, assim como seu ponto de partida, variam conforme as posiçōes políticas e/ou ideológicas assumidas pelos sujeitos enunciadores em seus discursos.

Assim, tomando por base as unidades léxicas, designationes, que se manifestam em seus discursos, os semas que integram seus sememas lingüisticos, torna-se possivel reconstituir o percurso do nivel cognitivo ao nivel semiótico ou, noutras palavras, a passagem da conceptualizaçāo à lexemização, do conceito à denominação. Temos, então, uma reconstrução do conceito $<<$ transgênico >> e seus correspondentes metaconceito e metametaconceito.

Preliminarmente, retomamos o esquema inicial do conceito lato sensu, aplicando-o ao conceito <<transgênico >

\section{Figura 5}

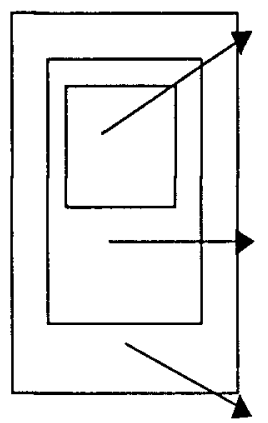

Noemas "universais" (I) $\cong$ "ser vivo geneticamente modificado por tecnologias avançadas de engenharia genética"; "processo de engenharia genética, de modiflcação do patrimônio genético (DNA) de um ser vivo".

Noemas ideológicos, culturais (II) $\cong$ "por exemplo, vegetais (sobretudo) e animais resistentes a doenças e pragas, de grande produtividade, mas com possiveis danos à saúde humana".

Noemas ideológicos, intencionais, modalizadores (III) $\cong$ por exemplo, no discurso politico de economistas, da agro-indústria, do comércio internacional etc., favorável à produção e consumo de alimentos transgênicos, "de alta produtividade", condiçāo para "matar a fome do mundo". No discurso 
político contrário, como, por exemplo, dos ecólogos, dos ambientalistas, dos responsáveis pela saúde pública etc., que “consideram prematuro ou precipitado produzir e distribuir alimentos transgênicos quando ainda nāo se conhecem com precisão os efeitos sobre o melo ambiente ou sobre os seres humanos e os animais que os consomem".

É possivel aplicar o modelo geral acima apresentado ao conceito lato sensu $<<$ transgênico $>$, de modo a construir uma formalização mais rigorosa do campo conceptual como conjunto unitário: <<transgênico〉>, apresentando sua estruturação e as relações que se estabelecem no interior do conceito lato sensu <<transgênico>> e os subconjuntos de traços semânticoconceptuais, ou seja, os metaconceitos e os metametaconceitos que o compōem. Temos, assim:

Campo conceptual como conjunto unitário: <<transgênico〉>

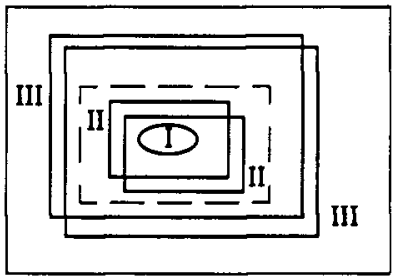

$$
\begin{aligned}
& \text { onde: } \quad[I=\text { [ }[+ \text { biológico], [+estrutura genética], [+tecnologia], } \\
& \text { [+mutaçăo]\} ミarquiconceito <<transgênico〉> } \\
& \text { ๓ conjunto de traços. "universais" }
\end{aligned}
$$

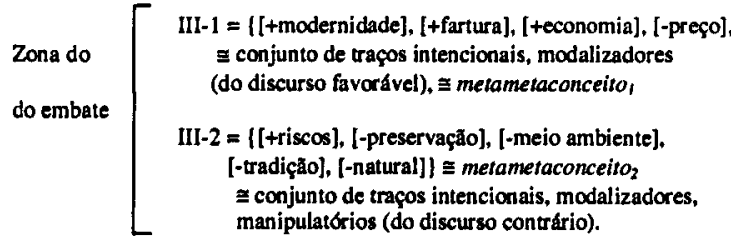

e onde: $\ll \ldots . .>>$ = conceito $e[. .]=$. traço semântico conceptual

\section{Figura 6}

TRADTERM, 7, 2001, p. 71-94 
Observemos que o subconjunto de traços semântico-conceptuais da Zona I, "universais", definem o arquiconceito como um consenso, relativo a aspectos da semiótica natural e da modificação, pelo homem, da semiótica natural, um "saber sobre o mundo" compartilhado pela comunidade.

Da mesma forma, os subconjuntos de traços semântico-conceptuais, ideológicos, culturais, da Zona II, constitutivos do metaconceito, definem certos consensos culturais, outra faceta do "saber sobre o mundo" compartilhado pela mesma comunidade, mas diferente de comunidade para comunidade.

Enfim, a Zona III se divide em dois subconjuntos de traços semântico-conceptuais, que constituem, respectivamente, o metametaconceito $_{1}$ e o metametaconceito ${ }_{2}$, enquanto conjuntos de traços intencionais, modalizadores, manipulatórios (dos discursos favorável e contrário).

Temos, então, a Zona III como a zona do embate, do confronto, particularmente no discurso politico mas também nos discursos científico, tecnológico, econômico etc.

Por outro lado, retomando o modelo semiótico e o modelo conceptual acima construídos, podemos opor <<biológico > ( trutura genética original, resultado da evolução das espécies”) e <<transgênico〉> ( = "estrutura genética modificada, por tecnologias da engenharia genética"), a que correspondem, respectivamente, como vimos, os conceitos <<artificial $>$ e $<<$ natural $>$, como também os termos que os manifestam.

O artigo publicado na Gazeta Mercantil (Pereira e Aliski, 4/ 09/2000, p.A-12) ilustra a zona de embate:

O Governo tem pressa para esclarecer as dúvidas que envolvem os organismos geneticamente modificados. Para isso, promove encontros com a midia especializada e realiza palestras sobre biossegurança. A iniciativa coordenada pelo Ministério da Ciência e Tecnologia busca dois objetivos: mostrar que o Pais tem uma legislação avançada sobre o assunto e que os técnicos brasileiros são capazes de distinguir o que faz bem à saúde do consumidor (...). 
O governo brasileiro está convencido de que precisa passar urgentemente um rolo compressor nas dúvidas sobre os organismos geneticamente modificados (OGMs) no Pais. Começou a sua parte na semana passada. O Ministério da Ciência e Tecnologia armou um encontro entre o comando da Comissão Técnica Nacional de Biossegurança (CTNBio) e profissionais de midia e interessados na divulgaçāo do tema transgênicos para ensinar a relevância do jornalismo científico no mundo moderno.

Juntou técnicos renomados, todos membros da CTNBio, para palestra sobre biossegurança. "Estamos plenamente conscientes da necessidade de incorporar a informação científica ao cotidiano de nossa população, utilizando os meios de comunicaçāo coletiva, impressos ou eletrônicos”, disse Esper Cavalheiro. secretârio de Políticas e Programas de Ciência e Tecnologia, representante do ministro da pasta, Ronaldo Sardenberg, na abertura do encontro. A discussāo sobre biossegurança envolve, hâ quase uma década, três corporações: cientistas, investidores e consumidores. Elas aparecem na composição da CTNBio, criada pelo governo em 1995. A maioria é cientista - por principio, defensores da pesquisa. São ligados ao governo pelo cordāo umbilical de institutos de pesquisa e universidades estaduais e federais. Os representantes das gigantes Novartis e Monsanto, presentes na CTNBio, carregam posições óbvias. O maior esforço da equipe nesta ofensiva de divulgação dos transgênicos é para firmar duas coisas: que o Pais tem legislação avançada neste assunto e que os técnicos brasileiros têm capacidade profissional para discernir sobre o que faz e o que não faz mal à saúde do consumidor. Os consumidores, a parte que ainda falta ser convencida, contam com dois representantes: uma funcionária pública do governo do Pará e um advogado do Mato Grosso do Sul. Na próxima semana, o Centro de Estudos Estratégicos do Ministèrio da Ciêncla e Tecnologia volta ao tema, numa parceria com a Fundação Konrad Adenauer, de São Paulo. Serão dols dias, 14 e 15, de debates sobre desenvolvimento e ética na biotecnologia. Enquanto isso, vem sendo adiada 
a divulgação da portarla de regulamentação da rotulagem de produtos com OGMs.

Quanto ao tipo de relação que se estabelece entre alimentos naturais $\mathrm{x}$ alimentos transgênicos, podemos dizer que são cohipônimos da semiótica natural e cultural:

Alimentos naturais $x$ alimentos transgênicos como cohipônimos da semiótica natural e cultural:

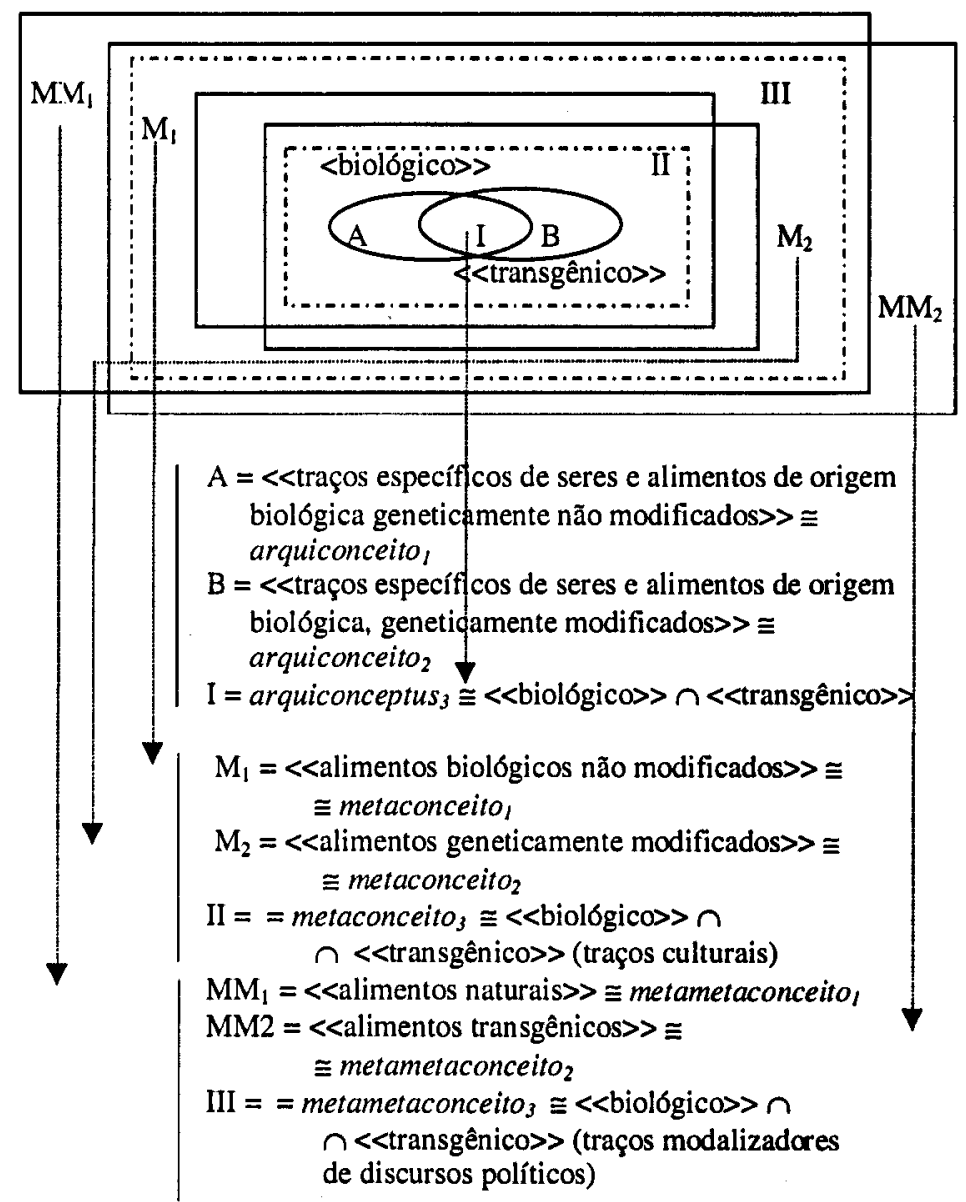

Figura 7

TRADTERM, 7, 2001, p. 71-94 
Ou, se preferirmos, de maneira mais especifica, a formalização abaixo, que apresenta uma amostra não exaustiva mas, apenas, ilustrativa dos traços semântico-conceptuais extraidos de discursos favoráveis ou contrários aos alimentos transgênicos:

Conceptus laro sensu:

Conceptus1 - alimentos biologicos naturais

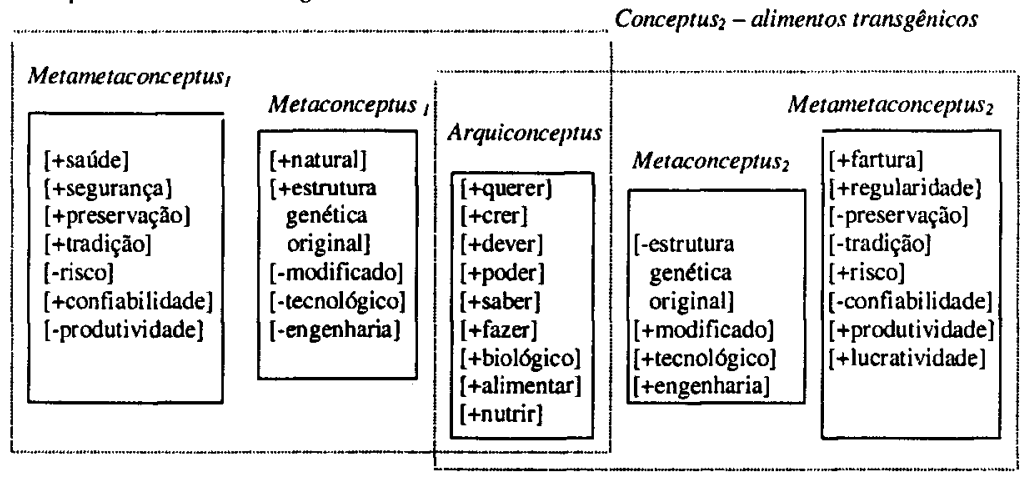

Figura 8: <<biológico > $x<<$ transgênico $>$, no nivel da semântica cognitiva

É de se ressaltar que não somente se torna cada vez mais nitida e precisa a configuração conceptual de <<transgênico >>, correspondente ao termo transgênico, como também o campo lexical/terminológico começa a se constituir progressivamente mais rico em unidades lexicais. No momento, cabe citar seres transgênicos, organismos geneticamente modificados, a sigla OGMs, dentre outros, que surgem como parassinônimos numa linguagem de especialidade (Barbosa, 1998b, p.385-405).

\section{Proposta de percurso metodológico, para a construçāo de um conceito}

Analisando os contextos que sustentam e manifestam essa complexa formação - neste caso, contextos constituidos de textos de especialistas e da mídia -, de que se extraem os traços 
conceptuais, formadores de um conceito, verifica-se que alguns desses contextos privilegiam o conceito stricto sensu, outros, o metaconceito e, outros ainda, o metametaconceito.

Propomos, a seguir, um modelo de ficha conceptual-terminológica que possibilita a descrição e análise desses três níveis de construção de um conceito.

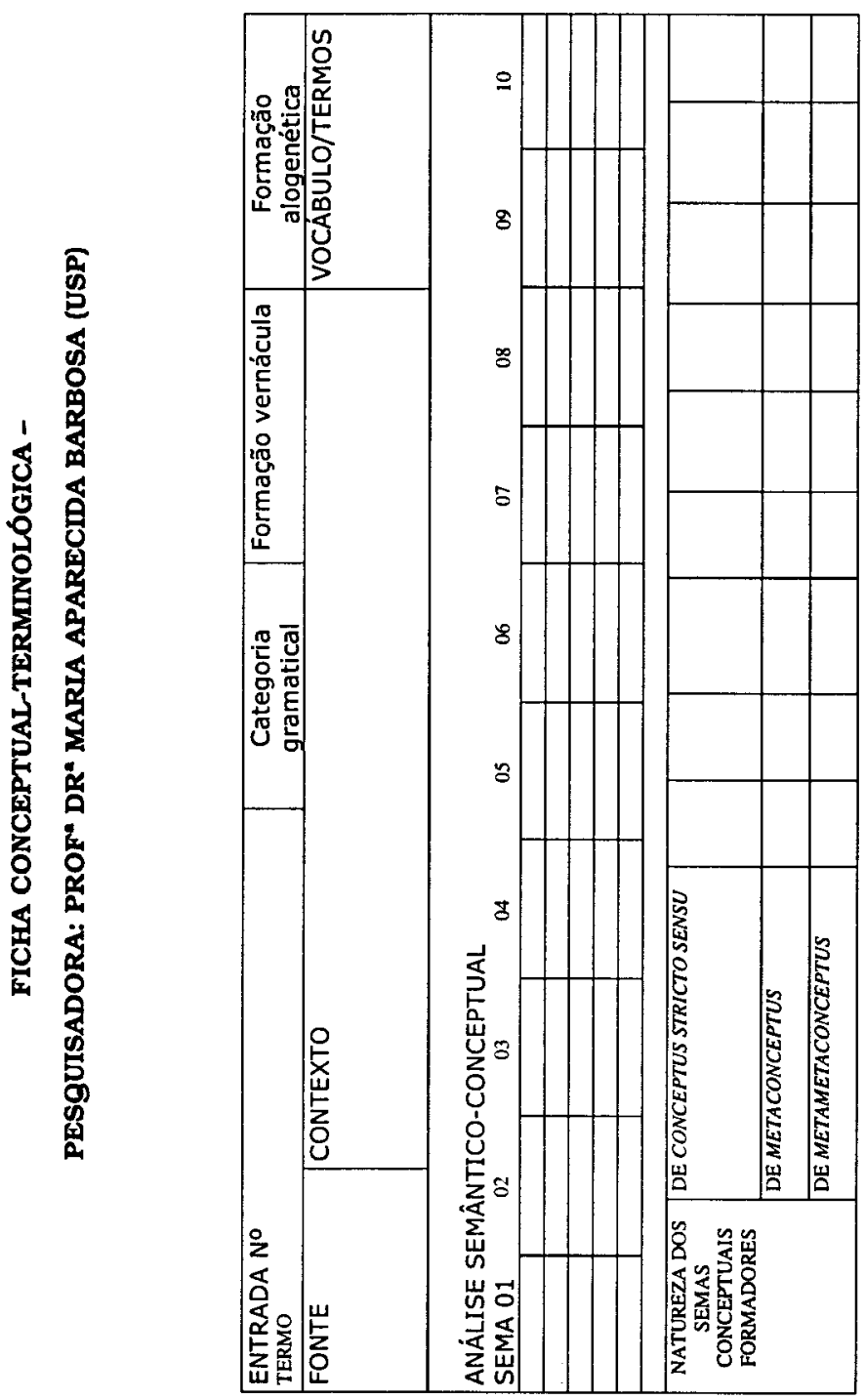

点

TradTerm, 7, 2001, p. 71-94 
Esta ficha conceptual-terminológica permite-nos, como dissemos, o registro dos contextos em que os caracterizadores conceptuais de um termo se apresentam. Permite, ainda, identificar o conjunto dos traços semântico-conceptuais (cf. figura 8), distinguindo os formadores do conceito stricto sensu, ou do metaconceito ou do metametaconceito, relacionando-os, enfim, aos vocábulos/termos que os manifestam.

Assim, por exemplo, no contexto "O Governo tem pressa para esclarecer as dúvidas que envolvem os organismos geneticamente modificados (...) O governo brasileiro está convencido de que precisa passar urgentemente um rolo compressor nas dúvidas sobre os organismos geneticamente modificados (OGMs) no País" (Pereira e Aliski, 04/09/2000, p.A-12) enfatiza-se o conceito stricto sensu.

Já os contextos, "Americanos aceitam bem os transgênicos. Pesquisa realizada no início de outubro pela GMA - Grocery Manufacturers of America (Manufaturadores de Alimentos da América) mostra que os americanos não vêem a biotecnologia como fonte de preocupaçāo e que não mudaram seus hábitos alimentares após a introdução de alimentos originários de plantas geneticamente modificadas no mercado. Além disso, a pesquisa também mostra que a maioria dos americanos acredita que a biotecnologia é um meio de melhorar as práticas agricolas e a qualidade dos alimentos" (Correio do Estado, 25/10/2000, p.6-A); "Parece claro, no entanto, que em muitos paises o aumento da produtividade acontecerá como auxilio de recursos biotecnológicos, com a tecnologia de modificação genética (ou tecnologia GM)" (Informativo do Instituto de Estudos Avançados, outubro-novembro 2000, p.1), acentuam o metaconceito.

Entretanto, no contexto "Em maio de 1999, quando os pesquisadores de uma universidade americana anunciaram que larvas de borboletas monarcas haviam morrido após se alimentarem de pólen de milho transgênico, isto é. geneticamente modificado (GM) (...) a noticia causou alvoroço. Grupos ambientalistas logo afirmaram, como em um folheto do Greenpeace, que "organismos geneticamente modificados podem desequilibrar ecossistemas naturais $e$ ameaçar a saude humana" $O$ Grupo Friends of the Earth preveniu, com alarde: "Existe um risco real de que as fazendas se transformem em território estéril para a vida selvagem." " (Harris, outubro de 2000, p.105-105), focaliza-se o metametaconceito. 
Quanto ao conjunto pleno dos traços semântico-conceptuais, são os que constam da figura 7, anteriormente apresentada.

Importa observar que a configuração do conceito lato sensu é um processo anterior ao processo da definição. Constitui ele sua própria forma de conteúdo. Noutras palavras, o conceito, conjunto ordenado de traços conceptuais, está contido na definição, mas nela adequa-se à estrutura sintático-semântica, sua forma de conteúdo e expressão, requerida por este tipo de discurso parafrástico, em que os traços conceptuais são organizados em forma de frase, ou seja, manifestados como metatermos. Ressalte-se, ainda, que, num dicionário terminológico, os dois subconjuntos ideológicos, o do metaconceito e o do metametaconceito, talvez devam aparecer em notas explicativas, campo previsto na microestrutura dos verbetes de um dicionário terminológico.

\section{Conclusão}

Constatamos a diversidade organizacional do conceito, com seus sucessivos conjuntos de traços caracterizadores, dos biológicos aos ideológicos, bem como a existência do processo de neutralização, também no plano conceptual, de que resulta o arquiconceito. Pudemos construir modelos que permitissem a descrição da estrutura dos campos conceptuais unitário e múltiplo, de seus respectivos arquiconceitos, metaconceitos e metametaconceitos, numa perspectiva mono e plurilingüe. Pudemos, também, propor metodologia de engendramento de conceitos no domínio terminológico. O modelo foi aqui aplicado à análise da formação do conceito correspondente ao termo transgênico, apresentando resultados bastante satisfatórios.

\section{Referências bibliográficas}

BARBOSA, M.A. (1998a) Terminologizaçāo, vocabularização, cientificidade, banalização: relaçōes. In: Acta Semiótica et Lingüistica, v.7. São Paulo, Plêiade, p.25-44. . (1998b) Paradigmas de criatividade léxica. In: Hommage à Simone Saillard. Textures. Cahiers du CEMLA. Lyon, Département de Langues Romanes de l'Université Lumlère Lyon 2, p.385-405. 
- (1999) Campo conceptual e campo lexical dos termos globalização e mundialização: relações. In: Revista brasileira de lingüistica, v. 10. São Paulo, Plêlade, p.29-52.

- (2000) Estruturas e tipologia dos campos conceptuais, campos semânticos e campos lexicais". In: Acta semiotica et linguistica, v.8. São Paulo, Plêiade, p.95-120.

BÉJOINT, H., THOIRON, Ph. et al. (1996) Notion d' "archi-concept" et dénomination. In: Meta. Journal des Traducteurs. Montréal, Presses de l'Université de Montréal, p.512-523.

CABRÉ, M.T. (1993) La terminologia. Teoria, metodologia, aplicaciones. Barcelona, Editorial Antártida/Empuries.

HARRIS, J.P. (2000) O que você deve saber sobre os transgênicos. In: Seleçōes, outubro de 2000. Rio, The Reader's Digest, p.101-105.

HJELMSLEV, L. (1975) Prolegômenos a uma teoria da linguagem. São Paulo, Perspectiva.

PAIS, C.T. (1993) Conditions sémantico-syntaxiques et sémiotiques de la productivité, systémique, lexicale et discursive. Thèse de Doctorat d'État. Paris/Lille, Université de Paris-IV, ANRT.

. (1998) Conceptualisation, dénomination, désignation, référence: réflextons à propos de l'énonciation et du savoir sur le monde. In: Textures. Cahters du C.E.M.I.A. Lyon, Université Lumière Lyon 2 , p.271-311.

. (1999) Semântica cognitiva, noêmica, semântica lexical e semiótica das culturas. In: SILVA. D.F. e VIEIRA, R. (orgs.) Ciências cognitivas em semiótica e comunicação. São Leopoldo, Ed. Unisinos, p.13-50. PEREIRA, P. e ALISKI, A. (2000) Campanha para promover os transgênicos. In: Gazeta Mercantil, 04/09/2000. São Paulo, p. A-12.

POTTIER, B. (1991) Théorie et analyse en linguistique. 2 éd. Paris, Hachette.

. (1992) Sémantique générale. Paris, P.U.F.

RASTIER, F. (1991) Sémantique et recherches cognitives. Paris, PUF. - (2000) Para uma poética generalizada. Trad. C.T. Pais. In: Acta semiotica et linguistica, v.8. São Paulo, Plèiade, p.445-470.

EDITORIAL (25/10/2000): Americanos aceitam bem os transgênicos. In: Correlo do Estado, 25/10/2000. Campo Grande, p.6-A. EDITORIAL (outubro/novembro 2000) Recomendaçōes sobre os transgênicos. In: Informattvo do Instituto de Estudos Avançados da Universidade de São Paulo, n. 61, ano XII. São Paulo, USP, p.1. 